\title{
Parametric Modeling of Assessing The Development Level of Economical Thinking of Students
}

\author{
Olimov Shirinboy Sharofovich, Sayfullaeva Nigora Zakiralievna
}

\begin{abstract}
The formation of professional competence of future specialists is determined by the acuteness of social, cultural and economic problems that are forming in the world. Modern higher education is aimed at finding acceptable ways to train professionally competent specialists, with a new way of thinking, with comprehensive knowledge, ready to independently solve professional problems. This article discusses one of the tools for assessing the development of economic thinking among students of higher educational institutions, which serves as a criterion for the selection and application of the most effective teaching technologies. Existing valuation models are designed primarily to determine the level of mastery of economic knowledge. In this study, the authors propose using not only the cognitive component, but also such parameters as the psycho-emotional component and the level of stereotyping of thinking. The relevance of this study is to identify the indisputable relationship of the forms, methods and content of education with the prospects for the development of their economic thinking, allowing them to become full members of society. Mastering the fundamentals of economic literacy at the present stage of development of society to achieve this goal is insufficient, the authors propose using the parametric assessment model they developed, accumulating achievements in such fields as pedagogy, economics, economic sociology and economic psychology.
\end{abstract}

Keywords : pedagogy, economics, economic sociology and economic psychology, pedagogical technology, innovative learning technologies.

\section{INTRODUCTION}

Education is the way and form of becoming a holistic person. The essence and purpose of the new education is the actual development of the general, generic abilities of a person, the development of universal methods of activity and thinking. Pedagogical technology is a well-thought-out model of joint pedagogical activity in designing, organizing and conducting the educational process with the unconditional provision of comfortable conditions for students and the teacher. Innovative learning technologies should be considered as a tool with which a new educational paradigm can be implemented.

Revised Manuscript Received on October 15, 2019.

* Correspondence Author

Olimov Shirinboy Sharofovich *, Doctor of Pedagogical Sciences, Professor of Pedagogy Department, Bukhara State University, shirinboy71@mail.ru

Sayfullaeva Nigora Zakiralievna, Doctorate student of Bukhara State University, nigora-sayfullaeva@mail.ru

\section{LITERATURE REVIEW}

For the first time, the concept of "economic thinking" was introduced by K. Marx $[4,181]$ in connection with criticism of the ideas of D. Mill and J.R. McCulloch in the chapter "The Decomposition of the Ricardian School." A detailed study of this phenomenon is found in authors such as L.I. Abalkin, A.Yu. Arkhipov, H.U. Astamirov, S.M. Belozerov, L.S. Blyakhman, M.L. Malyshev, V.V. Malykhin, A.A. Prokhorenko, E.V. Putekhina, V.V. Radchenko, I.B. Skorobogatov, K.A. Ulybin, V.D. Chukhlomin, N.V. Yartseva.

\section{RESEARCH METHODOLOGY}

The main goal of innovative educational technologies is to prepare a person for life in an ever-changing world. The essence of such training is to orient the educational process towards the potential of a person and their implementation. Education should develop mechanisms of innovative activity, find creative ways to solve vital problems, and contribute to turning creativity into a norm and a form of human existence.

The purpose of innovative activity is a qualitative change in the personality of the student in comparison with the traditional system. This becomes possible due to the introduction of didactic and educational programs not known to the practice in professional activities, which involves the removal of the pedagogical crisis. The development of the ability to motivate actions, to navigate independently in the information received, the formation of creative unconventional thinking, the development of students through the maximum disclosure of their natural abilities using the latest achievements of science and practice, are the main goals of innovation.

Innovative activity in education as a socially significant practice aimed at the moral self-improvement of a person is important because it is able to ensure the transformation of all existing types of practices in society [1, 438].

\section{DISCUSSION}

Economic society requires a sufficient level of education to be able to engage in professional activities and, at the same time, graduate mobility, which only stimulates the use of modern technologies. educational methodologies aimed at the 
implementation of the educational process taking into account the professional orientation of training, orientation toward a personal approach and personality-oriented teaching remain relevant $[2,126]$.

During the experiments it was found that under equal conditions, about $10 \%$ of the heard volume of information, $50 \%$ of the seen volume and more than $90 \%$ of what was the result of practical activity are stored in the student's memory. Based on this, we can conclude that the most rational way of learning is a method based on the active inclusion of the student in the action associated with the independent accumulation of useful information.

In the process of collecting economic information, students will be able to detect not only the characteristic phenomena of economic life, but also to predict, on the whole, the dynamics and evolution of the entire system of economic relations. Based on this, an important point is the acquisition of not ready knowledge, but the development of the ability to independently come to the right conclusions in the process of scientific search and analysis of the collected economic data.

\section{ANALYSIS AND RESULT}

In modern conditions, no one doubts that career growth is impossible without a good education. The labor market in conditions of modernization of the economy is extremely volatile. In this regard, graduates who are able to quickly change their profession and be ready for self-education and self-development become popular. One of the ways the state achieves these extremely important socio-educational, cultural and moral goals is the introduction of innovative forms of education, including the use of interactive classes $[3,40]$.

The modern concept of economic education provides for increasing the importance in the organization of the educational process of active forms of educational activity. Such teaching methods require for the development of the proposed educational material to attract knowledge that students acquire not only at the university, but also from additional sources of information. When choosing such sources, a special place is occupied by the generation of new information in the process of students participating in active forms of learning, which imitate practical situations in a conflict of interests of their participants.

It is quite possible to realize these skills using actively teaching case-study technology, writing an essay on an economic topic, a project method, business and role-playing games using practical situations [1, 439].

Among foreign authors in this connection we mention P. Heine, P. Boatke, D. Pritchitko; True, in their wording it is an "economic way of thinking" [5, 344].

Economic thinking refers to the process and result of reflecting economic reality; knowledge, abilities and skills of theoretical and practical handling of categorical economic apparatus, implemented in solving applied economic problems. The process of formation of economic thinking involves a combination of economic theory and practice in the activities of an individual group $[6,16]$.

\section{METHODOLOGY}

In order to identify the level of development of economic thinking among university students, experimental work was carried out in four regional universities of the country. In these universities, phased work was carried out, including questionnaires at the student level and at the level of teachers of economic disciplines, statistical processing of the data obtained, based on the conclusions made, master classes and round tables were prepared and conducted at the department, as well as classes using innovative pedagogical technologies that contribute to filling those gaps that were identified during the survey.

Participants were selected for the experimental and control groups, the level of development of economic thinking was analyzed before and after the experiment, a preliminary assessment of the impact of the proposed innovations on the development of economic thinking was made. The results of the experimental work served as the basis for the development of a model of psychological and pedagogical impact on students, based on innovative technologies for teaching economic disciplines and contributing to the development of economic thinking among students.

At the initial - formative stage of the experimental work among students, a survey was conducted to identify and evaluate the current state of the level of development of economic thinking among students. The number of students who participated in the survey was 445 people. The questionnaire was conducted in the form of testing, which included 15 questions with four possible answers. Questionnaire questions for students and analysis of the results of the questionnaire are given below.

Summarizing the above, we can conclude that students are clearly aware of the importance of economic knowledge and economic culture for their future activities and, in general, for the socio-economic development of the country. At the same time, most of them find it difficult to navigate the realities of today, since the educational system in which they study does not fully reveal their intellectual potential due to insufficient development of practical skills. A very small number of students can independently calculate the feasibility study for their ideas and projects.

Many people do not fully understand the meaning of the adopted legislative acts. About $70 \%$ of students advocate updating economic models for the development of society. An important conclusion is that more than a third of students include group work methods as effective methods of teaching economic disciplines, followed by development and game methods in relevance. Students realize that they need to learn how to work in a group before starting their professional activity, since it is these skills that will allow them to adapt effectively in a changing sociocultural environment and maximize their creative potential. 
Analysis of the results of preliminary testing of students showed that their economic thinking as such is not well developed. Therefore, the educational technologies that are used today in higher educational institutions of the republic, as well as the content of academic disciplines of an economic profile, do not contribute to the formation and development of economic thinking among students to a sufficient extent. An important area of activity for the formation and development of students' economic thinking is the definition and adequate selection of educational technologies that contribute to the realization of this goal in the specific pedagogical conditions.

Ninos Pierre Malek, in her dissertation, investigated the effectiveness of alternative methods of teaching economics, such as imitation, group activity, audio and visual teaching aids, and compared the effectiveness of using traditional teaching methods. Her research showed that the inclusion of alternative teaching methods as a complement to standard lecture classes does not have a significant impact on student learning, which was confirmed by measuring the level of economic thinking with preliminary and final testing [7].

From this we can conclude that the enrichment of the essentially traditional system of teaching pedagogical innovations does not significantly affect the effectiveness of the learning process, therefore, it is necessary to develop and apply fundamentally new approaches that can fundamentally change the learning paradigm.

The article by Omar Fernando Cortés Peña, Raimundo Abello Llanos, Marianela Denegri Coria, Andrés Manuel Pérez-Acosta "Multidimensional Model for Assessing the Economic Thinking of Students" provides a variation of the model for assessing the economic thinking of students.

The economic thinking of students, according to the authors, is a strategic aspect of research within the framework of higher education, given its critical impact on the development of skills and professional standards necessary for the implementation of scientific and technological innovations.

The main contribution of this study is to develop a multidimensional model for assessing economic thinking in terms of self-organizing systems. The methodology has an empirical-analytical approach.

The tools and results correspond to the perspective of an adaptive system based on the theory of answers of objects, a fractal model of competence in solving economic problems, knowledge of financial aspects, responsible consumption, sustainable development and understanding of the economic world.

An analysis of the multidimensional model of assessing economic thinking allows us to conclude that this model is more consistent with pedagogical behaviorism and, therefore, performs primarily an adaptive function, which is associated with the adaptation of the student, pupil to the specific requirements of the modern sociocultural environment, the ability to best benefit from a combination of knowledge and skills of an economic nature; the humanistic function aimed at the development of his personality, creative personality, in this model is weakly manifested.

Along with this, the model does not involve factors that directly reflect the thought processes that occur in the consciousness of the individual when making economic decisions

The model of economic socialization of Denegri deserves special attention.

In the model of economic socialization of Denegri, a person acts as a subject of complex relationships in the system of social and economic interaction. According to Denegri, economic choice is influenced by both the sociocultural environment and the prevailing stereotypes of the economic behavior of society.

Here, the learning process includes the study of models of interaction with economic reality. However, this model also does not contain practical guidance for the effective organization of the educational process at the university, which contributes to the development of students' economic thinking and the implementation of not only the adaptive, but also the humanistic function of the teaching profession [8].

The question of how to organize the educational process so that all students with, of course, various characteristics of thought processes, cognitive and analytical abilities, can fully master economic laws, principles and patterns, not only in order to learn to adapt to the greatest benefit to changing environmental conditions, but also to become full-fledged members of a society with an active civic position formed, still remains open.

There is the following classification of types of thinking depending on the types of training.

\begin{tabular}{|c|c|c|}
\hline [1] Type of training & [2] Character of mental operations & [3] Type of thinking \\
\hline $\begin{array}{l}\text { [4] Algorithmic } \\
\text { Learning }\end{array}$ & Exact copying of teacher and textbook & $\begin{array}{l}\text { [6] Reproductive Standard Thinking } \\
\text { [7] }\end{array}$ \\
\hline $\begin{array}{l}\text { [8] Descriptive } \\
\text { Learning }\end{array}$ & $\begin{array}{l}\text { [9] Semi-independent comprehension, transformation } \\
\text { and assimilation of educational material } \\
\text { [10] }\end{array}$ & $\begin{array}{l}\text { [11] Semi-independent } \\
\text { reproductive-variable thinking } \\
\text { [12] }\end{array}$ \\
\hline $\begin{array}{l}\text { [13] Problem-search } \\
\text { training } \\
\text { [14] }\end{array}$ & $\begin{array}{l}\text { [15] Self-synthesizing new concepts from elements of } \\
\text { existing knowledge } \\
{[16]}\end{array}$ & $\begin{array}{l}\text { [17] Independent creative, productive } \\
\text { thinking } \\
{[18]}\end{array}$ \\
\hline
\end{tabular}


In accordance with this classification, students were conditionally divided into three types:

1) with reproductive thinking;

2) with reproductive-variable thinking;

3) with productive thinking.

The parametric model for assessing the level of development of economic thinking includes three components:

1. Cognitive

2. Psycho-emotional

3. The level of stereotyping

To diagnose students' thinking, a special questionnaire was developed, which includes questions and answers related to the cognitive, psycho-emotional components and the level of stereotyping. Depending on how students answered questions from the questionnaire, it was determined which grade the level of development of their thinking relates to.

Cognitive component. The questions for the cognitive component had an economic orientation and served to $r$ eveal both the level of theoretical knowledge and the ability to apply them in everyday and educational activities. The questions had a different level of complexity, the basis for establishing the level of complexity in this component was B. Bloom's taxonomy. In his fundamental work, The Taxonomy of Educational Goals: A Field of Knowledge, the American scientist Benjamin Bloom tried to construct a hierarchy of educational goals covering a cognitive area that would describe step by step the levels of human thinking and the resulting learning objectives.

From Bloom's point of view, learning objectives are directly dependent on a hierarchy of thought processes, such as remembering, understanding, applying, analyzing, synthesizing, evaluating, and creating. Reproductive thinking corresponds to remembering, understanding; reproductive-variative - application and analysis (analizing), productive thinking - synthesis (evaluating) and evaluation (creating).

Psycho-emotional component. The questions for the psycho-emotional component also had economic content, but were focused on identifying the degree of dependence of the individual's thinking on the external psycho-emotional impact.

Economic sociology, interacting with economic psychology, considers a managing person not only as an individual thinking, weighing, calculating, but also - feeling, experiencing, expressing his attitude to facts, phenomena, events, other people in the form of emotions. Emotions are a complex of psychophysiological processes, an integral reaction of an individual, reflecting the attitude of the subject to the object of perception, arising, as a rule, in a situation of uncertainty.

Imbalance in the functioning of the mechanism of economic thinking can occur as a result of external psycho-emotional effects on the individual. As a result, a person becomes less organized in his thoughts and actions and, accordingly, more controlled. Among the emotions that color economic behavior, and thereby affect it, allocate active emotions (from the French. Acquisition - acquisition). They accompany the process of earning, acquiring, collecting, harvesting, etc.

These emotions are closely related to the areas of consumption and accumulation. The deep nature of such experiences is connected with a person's desire to satisfy his needs, achieve material security, feel economic freedom, etc. However, when a given set of emotions completely dominates a person, greed engulfs him, thereby opening up wide opportunities for controlling this person's economic behavior. The principle of managing people based on their greed has been applied since time immemorial.

Thus, the psycho-emotional component of an individual's economic thinking, on the one hand, contributes to the accumulation of positive economic experience associated with positive human experiences, and thereby focuses on the choice of emotionally acceptable, comfortable models of economic behavior, on the other hand, it can slow down or even block the operation of the rational components of this mechanism.

The psycho-emotional component of the parametric model was also divided into three gradations: high, medium, low. From the students' answers to questions from the block of the psycho-emotional component, the degree of their dependence on external influence was revealed. This information is very important for the development of measures to prevent irrational choices of economic thinking related, in particular, to the conscious formation of a stereotype of thinking that would prevent the adoption of important economic decisions in a state of increased emotional and psychological activation.

The level of stereotyping. The harsh conditions of competition and the ever-increasing flow of information from the objects of the outside world "forced" human thinking to develop internal auxiliary mechanisms to increase the efficiency of using limited mental resources.

The study of the level of stereotyping is important in that it allows you to determine students' commitment to standard behaviors, the degree of limited range of economic decisions in a changing environment.

Students, whose thinking is constrained by the framework of traditional ideas about economic phenomena, are incapable of creative and innovative solutions. The level of stereotyping in the parametric model for assessing the development of economic thinking is divided into three gradations: low, medium and high.

After conducting a comprehensive diagnosis based on the economic content questionnaire compiled by the authors at the preliminary stage of the experimental work, individual parameters of the students' economic thinking development level were determined in accordance with the three components of the model. Based on a generalization of the obtained data, a generalized structure of the ratio of three model parameters for the studied group of students to the application of innovative educational technologies for teaching economic disciplines was obtained. 
Result.Based on the above provisions, the authors developed a graphic display of the parametric estimation model, in which the three basic components of the estimation model were laid off along the $\mathrm{X}, \mathrm{Y}, \mathrm{Z}$ axes of the Cartesian coordinate system (Fig. 1).

Diagnostic results were estimated using the mathematical model we developed, which reflected three parameters: the cognitive component, the psycho-emotional component, and the level of stereotyping. To determine the gradation, a 10-point grading scale was used, which included 3 grading ranges for each parameter

The test for determining each of the components has 10 questions. The sum of the scores for each parameter is marked on the corresponding coordinate axis. The points obtained on each axis are connected by straight lines. The final conclusion is made by analyzing the configuration of the resulting triangle. At the same time, averaged values were accepted for the group, and not for the individual student, this is acceptable for analyzing the effectiveness of the application of innovative teaching technologies.

We presented the results of the experiment on the graph for all groups in which economic disciplines were taught using various methods: 1) traditional methods; 2) case study technology; 3) writing an essay; 4) project method; 5) role-playing game. The combination of the obtained graphs is presented in Figure 2.

We presented the results of the experiment on the graph for all groups in which economic disciplines were taught using various methods: 1) traditional methods; 2) case study technology; 3) writing an essay; 4) project method; 5) role-playing game. The combination of the obtained graphs is presented in Figure 2.

\section{COGNITIVE COMPONENT}

A conclusion section is not required. Although a conclusion may review the main points of the paper, do not replicate the abstract as the conclusion. A conclusion might elaborate on the importance of the work or suggest applications and extensions.

\section{CONCLUSION}

A conclusion section is not required. Although a conclusion may review the main points of the paper, do not replicate the abstract as the conclusion. A conclusion might elaborate on the importance of the work or suggest applications and extensions.

\section{REFERENCES}

1. G. O. Young, "Synthetic structure of industrial plastics (Book style with paper title and editor)," in Plastics, 2nd ed. vol. 3, J. Peters, Ed. New York: McGraw-Hill, 1964, pp. 15-64.

2. W.-K. Chen, Linear Networks and Systems (Book style). Belmont, CA: Wadsworth, 1993, pp. 123-135.

3. H. Poor, An Introduction to Signal Detection and Estimation. New York: Springer-Verlag, 1985, ch. 4.

4. B. Smith, "An approach to graphs of linear forms (Unpublished work style)," unpublished.

5. E. H. Miller, "A note on reflector arrays (Periodical style-Accepted for publication)," IEEE Trans. Antennas Propagat., to be published.
6. J. Wang, "Fundamentals of erbium-doped fiber amplifiers arrays (Periodical style-Submitted for publication)," IEEE J. Quantum Electron., submitted for publication. 